\title{
O PAPEL DO PROFESSOR NA MEDIAÇÃO DAS TECNOLOGIAS DIGITAIS DE INFORMAÇÃO E COMUNICAÇÃO (TDICs)
}

\author{
Bruno Santos de Oliveira ${ }^{1}$ \\ Daulinda Santos Muniz ${ }^{2}$
}

\section{RESUMO}

O presente trabalho tem como objeto de estudo O Papel do Professor na Mediação das Tecnologias Digitais da Informação e Comunicação (TDICs). Sua função como mediador e facilitador do processo de ensino e aprendizagem nos direciona para a reflexão sobre o conceito de ser professor, do seu papel e seus atributos para o exercício em sala de aula considerando o universo das Tecnologias Digitais da Informação e Comunicação (TDICs). Tem como Objetivo geral analisar o papel do professor na mediação das Tecnologias Digitais de Informação e Comunicação (TDICs); os objetivos específicos estão voltados em compreender como ocorre o uso das TDICs na prática docente em sala de aula; identificar a prática do professor no que concerne ao uso das TDICs e suas contribuições para a aprendizagem do aluno. A construção do referencial teórico se fez a partir de autores como: Arruda (2020), Branco (2019), Buckingham (2010), Luck (2014), Vedovatto (2014), Gewehr (2016) e Zacariotti e Sousa (2019). A problemática que norteia a pesquisa é: qual a função do professor no processo de ensino e aprendizagem subsidiado pelas Tecnologias Digitais da Informação e Comunicação? No processo metodológico, há a pesquisa bibliográfica, de natureza qualitativa, exploratória, com a pesquisa de campo e se estabelecendo no método indutivo, aplicando-se um questionário para o corpo docente da EMEB 3 de setembro, Bom Jardim - MA. O trabalho não se molda na perspectiva do criticismo sobre os diferentes atores aqui apresentados, nem tão pouco sobre os entrevistados ou a escola, mas se justifica no estudo acerca desse profissional sobre sua prática pedagógica. $\mathrm{O}$ artigo visa constatar que o professor é figura relevante para o processo de ensino e aprendizagem e nisto há de se discutir sobre sua prática, em concordância com o universo das TDICs.

Palavras-chave: Escola. Professor. Tecnologias Digitais da Informação e Educação (TDICs).

\footnotetext{
${ }^{1}$ Graduado em Licenciatura em Pedagogia pela Universidade Estadual do Maranhão. E-mail: bruno. adm1992@gmail.com

${ }^{2}$ Mestrado em Gestão de Ensino na Educação Básica pela Universidade Federal do Maranhão. E-mail; daulindasmuniz@hotmail.com
} 


\title{
THE TEACHER'S ROLE IN THE MEDIATION OF DIGITAL INFORMATION AND COMMUNICATION TECHNOLOGIES (ICTS)
}

\begin{abstract}
The object of the present work is The Teacher's Role in the Mediation of Digital Information and Communication Technologies (ICTs). Their role as a mediator and facilitator of the teaching and learning process directs us to reflect on the concept of being a teacher, their role and attributes for the classroom practice, considering the universe of Digital Information and Communication Technologies (ICTs). Its general objective is to analyze the teacher's role in the mediation of Digital Information and Communication Technologies (ICTs); the specific objectives are aimed at understanding how the use of ICTs occurs in the teaching practice at the classroom; identify the teacher's practice regarding the use of ICTs, and its contributions to student learning. The construction of the theoretical framework was based on authors such as: Arruda (2020), Branco (2019), Buckingham (2010), Luck (2014), Vedovatto Iza (2014), Gewehr (2016), and Zacariotti; Sousa (2019). The question that guides the research is: what is the teacher's role in the teaching and learning process supported by Digital Information and Communication Technologies? In the methodological process there is bibliographical research, of qualitative and exploratory nature, with field research and establishing itself in the inductive method, applying a questionnaire to the faculty of EMEB 3 de Setembro, Bom Jardim - MA. This article is not framed in the perspective of criticism about the different actors presented here, nor about the interviewees or the school, but it is justified in the study regarding this professional and their pedagogical practice. The article aims to verify that the teacher is a relevant actor in the teaching and learning process, and in this, it is necessary to discuss about their practice in accordance with the universe of ICTs.
\end{abstract}

Keywords: School. Teacher. Digital Information and Education Technologies (ICTs).

\section{EL PAPEL DEL PROFESOR EN LA MEDIACIÓN DE LAS TECNOLOGÍAS DE INFORMACIÓN Y COMUNICACIÓN DIGITALES (TDIC)}

\section{RESUMEN}

El presente trabajo tiene como objeto de estudio El Rol del Docente en la Mediación de las Tecnologías Digitales de Información y Comunicación (TDICs). Su rol como mediador y facilitador del proceso de enseñanza y aprendizaje nos encamina a reflexionar sobre el concepto de ser docente, su rol y sus atributos para el ejercicio en el aula considerando el universo de las Tecnologías Digitales de Información y Comunicación (TDICs). Su 
objetivo general es analizar el papel del docente en la mediación de las Tecnologías de la Información y la Comunicación Digitales (TDIC); los objetivos específicos están dirigidos a comprender cómo se produce el uso de los TDIC en la práctica docente en el aula; Identificar la práctica del maestro con respecto al uso de TDIC y sus contribuciones al aprendizaje de los estudiantes. La construcción del marco teórico se basó en autores como: Arruda (2020), Branco (2019), Buckingham (2010), Luck (2014), Vedovatto Iza (2014), Gewehr (2016) y Zacariotti; Sousa (2019). El tema que guía la investigación es: ¿cuál es el rol del docente en el proceso de enseñanza y aprendizaje apoyado por las Tecnologías Digitales de la Información y la Comunicación? En el proceso metodológico hay una investigación bibliográfica, cualitativa, exploratoria, de campo y de afianzamiento en el método inductivo, aplicando un cuestionario a la facultad de EMEB 3 de Setembro, Bom Jardim - MA. Este artículo no se enmarca en la perspectiva de la crítica sobre los diferentes actores aquí presentados, ni sobre los entrevistados o la escuela, sino que se justifica en el estudio sobre este profesional sobre su práctica pedagógica. La contribución de este artículo es hacer del profesor una figura esencial en el proceso de enseñanza y aprendizaje, y para ello es necesario discutir su práctica según el universo DTIC.

Palabras clave: Escuela. Maestro. Tecnologías digitales de información y educación (TDIC).

\section{INTRODUÇÃO}

Agente mediador do processo de ensino e aprendizagem, o professor é o ser que merece destaque pelo seu papel no contexto educacional. Dessa maneira, o presente artigo discorre sobre a necessidade de reflexão sobre o conceito de ser professor, do seu papel e seus atributos para exercício em sala de aula, considerando o universo das Tecnologias Digitais da Informação e Comunicação (TDICs).

Nesse contexto, entende-se que o professor atua para a formação do ser, interligando as diferentes esferas da vida do homem, da sociedade e do conhecimento, ou seja, nos múltiplos aspectos que constituem o ser, socioculturais, intelectuais, emocionais, afetivos, histórico, enfim, diversos. Por isso, entende-se que o "ser-professor" é também indivíduo que não nasce instantaneamente, mas que implica na compreensão da própria formação e que se constitui temporalmente.

Como agente mediador do processo de ensino e aprendizagem, esse deve também estar apto para atuar no contexto pedagógico das TDICs visando a aprendizagem, a orientação e a reflexão sobre os processos que implicam na atuação do alunado acerca dessas tecnologias na educação, possibilitando a formação de pessoas responsáveis e colaboradoras no mundo digital, estabelecendo ainda uma relação entre si e o aluno por meio da cultura do diálogo e o acompanhamento do contexto sociocultural dele. 
Diante disso, a escola também é posta como elemento de contribuição para a prática docente. Ela é a instituição que norteia o homem em seu processo de desenvolvimento, ou seja, o direcionamento da criança na compreensão de si, do outro e do meio, principalmente com a participação das tecnologias digitais em seu contexto sociocultural. Cabe também a ela atuar para que o professor desenvolva competências que direcionem sua ação em sala de aula, isso implica se atualizar a realidade incorporando a si o uso das TDICs em sala de aula.

A partir disso surge a temática "o papel do professor na mediação das Tecnologias Digitais de Informação e Comunicação (TDICS)", com o problema: qual a função do professor no processo de ensino e aprendizagem subsidiado pelas Tecnologias Digitais da Informação e Comunicação?

O presente artigo não se molda na perspectiva do criticismo sobre os diferentes atores aqui apresentados, nem tampouco sobre os entrevistados ou a escola, mas consiste no estudo acerca desse profissional sobre sua prática pedagógica. Por isso, o professor é figura relevante para o processo de ensino e aprendizagem e nisto há de se discutir sobre sua prática em concordância com o universo das TDICs e suas competências sobre essas precisam ser desenvolvidas para além do uso mecânico dessas ferramentas didáticas, objetivando o letramento digital dos envolvidos.

O trabalho utiliza como metodologia a pesquisa bibliográfica de caráter qualitativo, exploratório, de forma indutiva, utilizando a pesquisa de campo para a coleta de dados. A metodologia inclui, ainda, um questionário fechado aplicado somente aos professores da EMEB 3 de Setembro, Bom Jardim - MA, por meio do qual se buscou compreender a percepção do professor sobre suas habilidades acerca das TDICs, os elementos que contribuem para a formação do professor com relação às competências necessárias para uso das TDICs em sala de aula, como a formação inicial acadêmica e a escola como instituição que promove a continuidade, ou mesmo a formação inicial do professor sobre as TDICs.

\section{REFERENCIAL TEÓRICO}

\subsection{O papel do professor}

Dada a relevância da temática, é imprescindível refletir sobre os conceitos que definem tal indivíduo, enfatizar o papel do professor no contexto da educação, bem como as competências e habilidades que esses devem ter para o exercício da prática docente no âmbito escolar. 
sobretudo por seus horizontes pessoais, profissionais e culturais. [...] Sua atuação junto de seus alunos deve ser aberta, com forte liderança e perspectivas positivas orientadas para o sucesso. Professores com elevadas expectativas no sentido de fazer diferença na aprendizagem de todos e cada aluno são aqueles que mais contribuem para a formação desses. (LUCK, 2009, p. 21).

Na perspectiva de Luck (2009), o professor é o indivíduo que atua sobre a formação do discente, estabelecendo relação entre diferentes esferas do ser, da sociedade e do conhecimento, bem como fator de contribuição para a formação do alunado.

Para outros autores como Vedovatto et al. (2014, p. 276):

Pode-se dizer que 'ser-professor (a)' é uma construção angariada no decorrer de um longo processo, pois é preciso tempo para assimilar a formação, para aprender como agir, para tomar decisões e principalmente para se reconhecer como um formador das futuras gerações [...].

Para os autores, "ser-professor" é um processo construído que demanda compreensão da própria formação que se molda temporalmente. É entendido ainda que o processo de se tornar professor nunca finda, mas está sempre se construindo, se moldando de acordo com o momento. "A formação do professor não se concretiza de uma só vez, é um processo. Não se produz apenas cursando uma licenciatura, neste caso, a Pedagogia. [...]" (BOAVENTURA, 2009, p. 41). Dessa forma, observa-se o professor como ser participativo, formado academicamente, mas que ainda possui um longo caminho a trilhar na jornada para a prática docente.

Nessa perspectiva, evidencia-se que o professor em sua carreira de docência necessita se qualificar profissionalmente. Nesse sentido, é preciso observar os dados dos princípios da educação que envolvem a Lei de Diretrizes e Bases do artigo 2 da Lei $n^{\circ}$ 9.394, de 20 de dezembro de 1996 que "desenvolve ao educando, seu preparo para o exercício da cidadania e sua qualificação para o trabalho" (BRASIL, 2019, p. 8).

O professor é norteado pelo seu papel no exercício da docência, tendo como alvo o aluno e sua formação envolvendo as esferas socioculturais, política, econômica, do conhecimento e para atuação de forma reflexiva e transformadora na sociedade, de forma que compreenda seu papel na busca pelos seus direitos e deveres como um cidadão.

[...] Otrabalho docente assume grande responsabilidade, pois a profissão de professor tem como objetivo a formação dos educandos, o trabalho com o conhecimento e cabe ao professor o domínio dos conhecimentos sejam eles pertinentes à área de formação, à área pedagógica, dentre outros, para que possa trabalhar em sala de aula como mediador do processo ensino-aprendizagem, no sentido de intermediar as relações dialógicas em sala de aula, estabelecer a relação interdisciplinar entre as áreas do conhecimento [...] (ZANON; MENDES, 2009, p. 42). 
Mediar o processo de ensino e aprendizagem é um dos pilares da finalidade do exercício docente, sua atuação implica no processo de interligar as diferentes esferas do conhecimento numa ação interdisciplinar, propondo e construindo situações em que aconteça o processo de construção do conhecimento, da cultura do diálogo, da reflexão sobre a relação ente ele e o outro dentro e fora da sala de aula. Quanto aos outros pilares, Assmasnn (2009, p. 31) ressalta "o professor - mediador, orientador e agente de mudança social".

Nesse sentido, há de se pensar sobre as competências e habilidades do professor, dado que seu trabalho com as TDICs implica também na sua ação mediadora do uso dessas novas ferramentas didáticas, visando à aprendizagem do aluno e letramento digital $^{3}$, além da orientação acerca do processo de pesquisa, reflexão sobre o processo de interação e socialização entre os demais alunos e colegas no mundo virtual ou no ciberespaço, contribuindo ainda para a cultura de pessoas responsáveis no uso das TDICs.

Ciberespaço é o espaço das comunicações por rede de computador. Sua comunicação acontece de forma virtual. Faz uso dos meios de comunicação modernos, destacando-se entre eles a Internet. Esse fenômeno se deve ao fato de, nos meios de comunicação modernos, existir a possiblidade de pessoas e equipamentos trocarem informações das mais variadas formas sem preocupações. (ZACARIOTTI; SOUSA 2019, p. 5).

Para Branco (2019, p. 4) a competência:

É um conjunto de conhecimentos (saberes), habilidades (saber fazer) e atitudes (saber ser); manifestam-se por comportamentos observáveis; trazem implícitos os conhecimentos tecnológicos e as atitudes, e valores inerentes à realização do trabalho.

Os processos que se articulam no "ser-professor" envolvendo as dimensões: intelectual, prática e social possibilitando ao indivíduo tomar decisões lógicas em situações adversas, bem como montar estratégias e aplicá-las. Ainda segundo Perrenoud (2015, p. 6 apud BRANCO, 2019, p. 16), "Uma competência orquestra um conjunto de esquemas. Envolve diversos esquemas de percepção, pensamento, avaliação e ação". No exercício da docência, o professor articula uma série de esquemas, moldando-os a partir da sua realidade e necessidade, objetivando uma melhor didática, traçando meios que possam dar continuidade ao processo de ensino e aprendizagem.

Diante disso, com relação às TDICs o professor também precisa desenvolver, ou já possuir, competências acerca da utilização dessas novas tecnologias, Branco (2019,

\footnotetext{
${ }^{3}[\ldots]$ Letramento digital é bem mais do que uma questão funcional de aprender a usar o computador e o teclado, ou fazer pesquisas na web, [...]. Mas parar por aí é confinar o letramento digital a uma forma de letramento instrumental ou funcional: as habilidades que as crianças precisam em relação à mídia digital não são só para a recuperação de informação. Como com a imprensa, elas também precisam ser capazes de avaliar e usar a informação de forma crítica se quiserem transformá-la em conhecimento (BUCKINGHAM, 2010, p. 49).
} 
p. 6) destaca uma das muitas outras competências básicas do professor: o conhecimento tecnológico. Esse se refere aos processos didáticos em que o docente precisa articular diferentes estratégias, com as múltiplas tecnologias presentes e que podem ser utilizadas para mediar o ensino.

Para isso, Pereira (2008, p. 12) frisa a relação entre professor e aluno no desencadeamento do processo de ensino e aprendizagem e afirma que esse somente é possível quando os dois estão presentes e atuantes, pois "quando existe diálogo, compreensão, respeito mútuo e a afetividade, há interação e consequentemente a esperada aprendizagem".

Gewehr (2016, p. 47) ressalta que:

[...] para que a aprendizagem ocorra cabe ao professor oportunizar estratégias de aprendizagem que despertem a emoção dos alunos, tornando interessante o conteúdo. Sendo estimulado, o aluno está passível a uma melhor recordação, já que o estímulo e a curiosidade mexem com sua emoção.

O professor, nesse processo, "assume o papel de facilitador da construção do conhecimento pelo aluno", (PEREIRA, 2008, p. 12). Isso se deve à sua prática pautada pelas novas estratégias ou metodologias norteadas pelas TDICs postas em sala de aula. Isso resulta no ensino caracterizado pela diversidade e inovação dos meios. Porém, Pereira (2008, p.13) ressalta que:

A inovação não está restrita ao uso da tecnologia, mas também a maneira como o professor vai se apropriar desses recursos para criar projetos metodológicos que superem a reprodução do conhecimento e levem à produção do conhecimento.

Mesmo na pandemia do Coronavírus ${ }^{4}$, o professor precisa quebrar as barreiras impostas pelo isolamento social, acreditando em sua prática, na capacidade de interagir e se relacionar com seus alunos e com o mundo por meios desses recursos digitais tecnológicos, que no presente momento estabelecem a relação entre indivíduos em diferentes espaços. Essa inovação e estratégias também se aplicam à presente situação da pandemia, ou seja: "cabendo ao professor conhecer e avaliar o potencial das diferentes mídias ao seu alcance e oportunizar o uso consciente por seus alunos" (PEREIRA, 2008, p.15).

Contudo, tais competências também podem ser desenvolvidas a partir de iniciativa da escola, essa é essencial na preparação do espaço, na capacitação e uso dessas ferramentas didáticas pedagógicas pelos professores e alunos.

\footnotetext{
${ }^{4}$ [...] Observa-se a emergência de um novo vírus, surgido em território Chinês em fins de 2019 [...] possui alto grau de contaminação [...] essas características permitiram ao novo Coronavírus (SARS-CoV-2) e a doença causada por ele (COVID-19) se tornarem uma das maiores epidemias da História, afetando todos os países e criando, possivelmente, a maior política de isolamento social já vista. (ARRUDA, 2020, p. 258).
} 


\subsection{O papel da escola}

Pela sua formação social e pessoal, a escola é a instituição que norteia o homem em seu processo de desenvolvimento. O conhecimento de mundo, as relações entre as pessoas e culturas se iniciam no ambiente escolar, logo, é neste espaço que o professor exerce sua prática.

Para a educação contemporânea crítica, a escola se consolida como a instituição capaz de criar condições que garantam o aprendizado de conteúdos necessários para a vida em sociedade, oferecendo instrumentos de compreensão da realidade, bem como favorecendo a participação dos educandos em relações sociais diversificadas. [...] (ASSMASNN, 2009, p. 19).

É na instituição escolar que a criança é direcionada a compreender a si, o outro e o seu meio social, adquirindo uma postura de aceitação das diferenças entre as demais, bem como estimular a aprendizagem através de metodologias que contemplem sua realidade e suas experiências adquiridas no seu meio social e familiar.

A escola é uma organização social constituída pela sociedade para cultivar e transmitir valores sociais elevados e contribuir para a formação de seus alunos, mediante experiências de aprendizagem e ambiente educacional condizentes com os fundamentos, princípios e objetivos da educação. O seu ambiente é considerado de vital importância para o desenvolvimento de aprendizagens significativas que possibilitem aos alunos conhecerem o mundo e conhecerem-se no mundo, como condição para o desenvolvimento de sua capacidade de atuação cidadã. (LUCK, 2009, p. 20).

Pela sua relevância como espaço de transformação, formação de pessoas e transformadoras de sua realidade, cabe à escola atuar de maneira que os professores em exercício desenvolvam competências que direcionem a prática docente contemplando assim os objetivos de ensino. Luck (2009) enfatiza o desenvolvimento de competências pelos profissionais que atuam na educação, considerando-as como condição de aprimoramento de sua identidade profissional.

A escola precisa estar contextualizada à realidade, isso inclui as TDICs, independentemente do cenário de pandemia em que se aderiu a novos meios de ensino mediados por elas, mas trata-se de se adaptar às novas formas de organização da sociedade atual, sua linguagem, seus novos espaços de convívio e sua cultura.

Gewehr (2016, p. 18) destaca que "aproveitar as TDICs deve ser visto como prioridade nas escolas, visto que os alunos tornaram-se midiáticos, consumindo frequentemente tecnologias". Logo, é imprescindível essa reflexão e implantação das novas tecnologias em seu âmbito, para que também o alunado saiba lidar com esse cenário que se transforma e é transformador. 
A escola é construtora de conhecimento crítico que busca a transformação social, para Assmasnn (2009, p. 9):

Enfim, a escola, na sociedade contemporânea, deve considerar que: as novas tecnologias mudam o conceito de tempo, espaço e ensino; cabe à educação o desenvolvimento integral da pessoa humana; o homem deve estar apto a viver em uma sociedade tecnológica e globalizada; não muda apenas o modo de aprender na escola, mas aquilo que se necessita saber; muda o eixo dos conteúdos para as competências e habilidades.

A escola em seu âmbito de atuação, compreendendo a realidade e a necessidade que o processo de desenvolvimento do educando exige, deve mobilizar meios e formas para propor uma educação inclusiva digital para todos os envolvidos, professores e alunos. O primeiro, no sentido de incentivar e abrir espaço para a inserção e aceitação do ensino subsidiado pelas TDICs, além da formação continuada. O segundo, no sentido de ter acessibilidade, desenvolvimento social crítico e construção de conhecimento, pois se aquela não atuar de forma precisa sobre as novas tecnologias em sala de aula, o processo de ensino e aprendizagem é comprometido.

Gewehr (2016, p. 43) destaca que:

O desafio da escola é desenvolver condições que permitam uma eficiente formação crítica dos jovens em relação às mídias, de modo que os alunos tenham condições de refletir e pensar criticamente sobre qualquer assunto. E que ainda se torna também responsabilidade da escola possibilitar aos alunos conhecimentos tecnológicos básicos.

As novas tecnologias devem ser pensadas e inseridas de forma reflexiva, em regime de colaboração, pela escola e professores, considerando que a sociedade atual está caracterizada como tecnológica. A Lei de Diretrizes e Base da Educação Nacional (LDB) n. ${ }^{\circ}$ 9.394/1996 menciona no art. $13 .^{\circ}$, inciso $V$, que para o professor compete "[...] participar integralmente dos períodos dedicados ao planejamento, à avaliação e ao desenvolvimento profissional”. (BRASIL, 1996). Ou seja, o que inclui a formação continuada nos diferentes aspectos do exercício. A escola também deve incentivar ou sugerir formações que adentrem tal cenário, incorporando as políticas pedagógicas internas da própria, ou seja, o Projeto Político-Pedagógico (PPP) ${ }^{5}$, construindo assim a identidade da instituição baseada nos novos meios de aprendizagens mediados pelas TDICs, do contrário, o aluno terá dificuldades em utilizar as ferramentas, dado que os próprios docentes não estão prontos para atuar com elas.

\footnotetext{
${ }^{5}$ É um projeto elaborado de forma participativa e colaborativa, originado no seio da coletividade docente, funcionários, alunos e pais, que dá uma identidade à instituição educacional [...]. O Projeto Político-Pedagógico [...], tem como foco o aluno, a sua formação e aprendizagem e a organização do processo pedagógico para promover essa formação e aprendizagem [...]. (LUCK, 2009, p. 38).
} 
[...] O trabalho específico da escola é proporcionar um conjunto de práticas planejadas com o propósito de contribuir para que os alunos assimilem determinados elementos culturais, considerados essenciais para seu desenvolvimento e para a sociedade, que, dificilmente seriam adquiridos sem uma orientação específica. (ASSMASNN, 2009, p. 5).

Logo, tais elementos culturais mencionados também incluem as tecnologias, que já há muito tempo adentraram o convívio e as práticas do homem, o próprio professor já as possui em seu convívio familiar e social, o que precisa é direcioná-las para sua prática, transformando tais ferramentas tecnológicas digitais em instrumentos didático-pedagógicos que subsidiarão o processo de ensino e aprendizagem.

\section{METODOLOGIA}

A construção do presente trabalho está pautada na pesquisa bibliográfica, "elaborada a partir de material já publicado" (PRODANOV; FREITAS, 2013, p. 54), de natureza quantitativa ${ }^{6}$, exploratória. Nesse aspecto, Prodanov e Freitas (2013) caracteriza-a como de planejamento flexível que envolve o levantamento bibliográfico e entrevista com sujeitos que tiveram experiência com o que se pretende pesquisar, "utilizada com o objetivo de conseguir informações e/ou conhecimentos acerca de um problema" (LAKATOS, 2003, p.186). No processo de coleta de dados, foi aplicado um questionário fechado com cinco questões a sete professores da Escola Municipal de Educação Básica 3 de Setembro em Bom Jardim - MA, situada no Projeto de Assentamento (PA) Antônio Conselheiro, no Sul do município, zona rural.

O trabalho tem por finalidade compreender o papel do professor na mediação das Tecnologias Digitais de Informação e Comunicação (TDICs), assim como os aspectos que contribuem para a formação e colaboração do desenvolvimento das competências direcionadas às TDICs como instrumentos didático-pedagógicos, ressaltando ainda que o presente trabalho não tem por finalidade o criticismo acerca dos professores e nem tão pouco sobre a EMEB 3 de Setembro, mas abre espaço para discussão e reflexão sobre o professor, as TDICs e a escola.

\section{RESULTADOS E DISCUSSÃO}

A partir dos dados obtidos pelo questionário aplicado aos professores da EMEB 3 de Setembro, pode-se notar precedentes que favorecem o professor no seu processo

\footnotetext{
${ }^{6}$ Para efeito de um maior esclarecimento, o seu objetivo é mensurar e permitir o teste de hipóteses, já que os resultados são mais concretos e, consequentemente, menos passíveis de erros de interpretação (FRASSON; OLIVEIRA JUNIOR, 2010, p. 96).
} 
de ensino e aprendizagem, assim como ter dimensão da participação da escola em dar continuidade à formação e desenvolvimento das competências necessárias para a efetivação do uso das TDICs em sala de aula. Observe abaixo o questionário:

1 - Com relação às Tecnologias Digitais da Informação e Comunicação - TDICs, como você classifica suas habilidades no momento de usá-las?

Ruim $\square$ Regular $\square$ Bom $\square$ Ótimo $\square$

"Regular" foi a resposta mais marcada, equivalendo a $71 \%$ dos entrevistados, enquanto que "Bom" foi a resposta de menor incidência, representando 29\%. Todavia, é fundamental entender que o que se tem é uma base do que se pode ser implementado posteriormente.

\section{2 - Das TDICs abaixo, qual(ais) delas você apresenta dificuldades em utilizar? PC/ Notebook $\square$ Celular $\square$ Tablet $\square$ Todos $\square$ Nenhuma $\square$}

O PC/Notebook se apresentou como o item de maior dificuldade de uso efetivo, equivalendo a $57 \%$ dos entrevistados, enquanto que $43 \%$ responderam nenhuma, as múltiplas tarefas e configurações complicam o trabalho do professor, já que pouquíssimos professores possuem um PC/Notebook em casa e a escola não possui em quantidade necessária para uso de todos.

3 - As redes sociais também são ótimos instrumentos de comunicação e informação que podem ser usadas ainda como plataforma de postagens de videoaulas, ou abrir uma página específica. Sobre a rede social WhatsApp:

\subsection{Sabe postar fotos/ imagens e vídeos? Sim $\square$ Não $\square$ \\ 3.2 Compartilhar fotos/imagens, vídeos? Sim $\square$ Não $\square$ \\ 3.3 Compartilhar informações de outras páginas ou sites? Sim $\square$ Não $\square$ \\ 3.4 Enviar mensagens via áudio ou escrita? Sim $\square$ Não \\ 3.5 Criar grupo de cunho didático? Sim $\square$ Não $\square$ \\ 3.6 Fazer chamada de vídeo com mais de cinco pessoas? Sim $\square$ Não $\square$}

O "sim" prevaleceu em todas as respostas da questão acima, ou seja, 100\% dos entrevistados. As redes sociais revelam o acompanhamento do professor diante das tecnologias digitais e as novas formas de comunicação e interação da sociedade moderna. Isso é um fator de grande importância para o professor, já que os permite acompanhar o contexto sociocultural, visando às novas formas de ensino e aprendizagem mediadas por essas ferramentas. 
4 - No seu processo de formação docente, a instituição de ensino em que você cursou fez menção ou abordou as TICs, ou TDICs para o processo de ensino e aprendizagem? $\operatorname{Sim} \square$ Não $\square$

Dos entrevistados, $71 \%$ afirmaram ter recebido formação acerca das tecnologias educacionais, enquanto que $14,5 \%$ afirmam não ter recebido esse tipo de formação, os outros $14,5 \%$ não responderam o questionamento. Neste momento, não se pretendeu desconsiderar os conhecimentos dos docentes acerca das tecnologias educacionais, por isso utilizou-se duas terminologias: Tecnologias da Informação e Comunicação (TICs) e Tecnologias Digitais da Informação e Comunicação (TDICs).

\section{5 - A Instituição de ensino em que atua promoveu alguma formação ou abordou a temática das TICs ou TDICs para o processo de ensino?}

$\operatorname{Sim} \square$ Não $\square$

Dos entrevistados, 86\% responderam que não, a escola não se atentou para a temática das TDICs em seu contexto, enquanto que 14\% disseram que sim. É necessário entender também que isso poderia ter acontecido em anos anteriores e não precisamente no ano de início da pandemia do Coronavírus.

A instituição exerce grande papel nesse contexto do professor, sua participação consiste em estar atenta aos novos processos de ensino e aprendizagem em consonância com a realidade do aluno, bem como, motivar o professor a fazer parte desse novo cenário, até mesmo contribuir para o desenvolvimento de competências no cenário das TDICs, possibilitando ao professor ir além do uso mecânico dessas ferramentas tecnológicas em sala de aula.

\section{CONSIDERAÇÕES FINAIS}

O professor é o ser que está diretamente ligado ao aluno pelo processo de ensino e aprendizagem. O professor é figura relevante para que isso aconteça, sua ação de mediar implica na concepção de quem ele é, do seu papel e das suas competências na prática pedagógica, adentrando o universo das Tecnologias Digitais da Informação e Comunicação TDICs e fazendo delas seu instrumento didático-pedagógico.

Compreende-se o professor como agente ativo que atua sobre o processo de formação e desenvolvimento do discente, envolvendo as diferentes esferas da vida do ser, ou seja, numa relação entre construção de conhecimento, da vida em sociedade constituída por diferentes pessoas de diferentes aspectos socioculturais e com o meio, ou seja, a relação entre si, o outro e o mundo. Nisto, ele assume a tarefa de orientar as futuras 
gerações para além da formação estudantil, para exercer seus direitos e deveres, situando o aluno desde cedo como individuo colaborador, que reflete e busca transformar a sua realidade para o bem comum de todos.

No seu exercício, o professor assume o papel de mediador do processo de ensino e aprendizagem com o aluno, propondo situações de aprendizagens interdisciplinares entre as diferentes esferas do conhecimento, estabelecendo um ambiente de relações dialógicas e reflexivas do ser. Dessa forma, o professor também deve pensar sobre as competências e habilidades acerca das Tecnologias Digitais da Informação e Comunicação - TDICs. Isso implica na sua ação mediadora do uso dessas novas ferramentas didáticas, no processo de ensino e aprendizagem do aluno, na orientação sobre a ação de pesquisa e de reflexão na interação e socialização entre os demais no mundo virtual ou no ciberespaço. Mesmo o professor não estando ainda atualizado, ele necessita desenvolver essas competências acerca das TDICs, por conta da realidade do aluno e das possibilidades de aprendizagens possibilitadas por elas.

A ação pedagógica vai além do uso mecânico das TDICs, como indivíduo facilitador da construção de conhecimento, a prática do professor será pautada pelas novas estratégias e metodologias, objetivando o letramento digital desses discentes que já experimentam uma realidade norteada pelas tecnologias, mesmo antes da pandemia do Coronavírus.

Diante disso, a escola também é posta como elemento de contribuição para a prática docente, pois a mesma norteia o homem em seu processo de desenvolvimento, ou seja, o direcionamento da criança na compreensão de si, do outro e do meio, principalmente com a participação das tecnologias digitais em seu contexto sociocultural. Dessa forma, cabe também a escola atuar para que o professor desenvolva competências que direcionem sua ação em sala de aula; isso implica atualizar a realidade incorporando a si o uso das TDICs no espaço escolar.

Para o professor, a escola oportuniza e incentiva o uso dessas tecnologias em sala de aula, bem como propõe a continuidade da formação docente sobre as TDICs, incluindo-as ainda ao seu Projeto Político Pedagógico - PPP, passando a fazer parte da sua identidade o letramento digital de todos os envolvidos, professores e alunos.

Assim temos o professor como elemento indispensável no processo de inserção das TDICs, ele atua como mediador e facilitador do processo de ensino e aprendizagem, inserindo ao seu fazer pedagógico essas tecnologias, de forma a proporcionar o letramento digital de seu alunado. A partir da pesquisa, notou-se também a relevância da formação inicial, pois o docente adentra os conceitos e formas de ensino promovidos pelas TDICs.

Em paralelo ao que foi exposto, a escola atua também para que o docente tenha subsídios teóricos e práticos para o uso dessas TDICs em sala de aula, proporcionando 
meios para que essas possam ser acessíveis aos professores, bem como o seu uso, de forma a promover aprendizagem e formação de alunos críticos e reflexivos. Por isso, a escola também deve se ater à sua função em promover a discussão, a reflexão e a conscientização acerca das TDICs como instrumentos didáticos da prática docente e elementos contribuintes ao processo de ensino e aprendizagem.

Espera-se que este trabalho possa contribuir para a reflexão do trabalho docente enquanto mediador na utilização das TDICs, bem como na construção de referencial teórico para futuras discussões acerca dos atores envolvidos nesse processo por parte do professor e da escola, tendo em mente a urgência da implantação das TDICs em sala de aula e seu uso efetivo pelos docentes como instrumentos didáticos pedagógicos capazes de promover e subsidiar o ensino e aprendizagem.

\section{REFERÊNCIAS}

ARRUDA, E. P. Educação remota emergencial: elementos para políticas públicas na educação brasileira em tempos de Covid-19. Em Rede - Revista De Educação a Distância, São Paulo, v.7, n. 1, p. 257-275, 2020. Disponível em: https://www.auni rede.Org.br/revista/index.php/emrede/article/view/ 621. Acesso em: 21 maio. 2021.

ASSMASNN, Hugo. A educação no contexto da sociedade contemporânea e o papel da didática. In: LARCHERT, J. M. Didática e Tecnologia. Bahia: UESC. 2009. Disponível em: https://ava2.uemanet.uema.br/mod/folder/view.php?id=24718.Acesso em: 21 maio. 2021.

BOAVENTURA de Sousa Santos. O conhecimento teórico: cultura e método na docência. In: LARCHERT, J. M. Didática e Tecnologia. Santa Catarina: UESC, 2009. Disponível em: https://ava2.uemanet.uema. br/mod/folder/view.php?id= 24718. Acesso em: 21 maio. 2021.

BRANCO, Priscila de Sousa Barbosa. As competências que o professor deve ter para ensinar. São Luís: Uemanet, 2019. 10 slides.

BRASIL. LDB: Lei de Diretrizes e Bases da Educação Nacional. 3. ed. Brasília: Senado Federal, Coordenação de Edições Técnicas, 2019. Disponível em: https://www2.senado. leg.br/bdsf/bitstream/handle/id/559748/lei_de_diretrizes_e_bases_3ed.pdf. Acesso em: 10 maio. 2021.

BRASIL. Lei n 9.394, de 20 de dezembro de 1996. Estabelece as diretrizes e bases da educação nacional. Diário Oficial da União, Brasilia, DF, 20 dez. 1996. Disponível em: http://www.planalto.gov.br/ccivil_03/leis//9394.htm. Acesso em: 20 março. 2021. BUCKINGHAM, D. Cultura digital, educação midiática e o lugar da escolarização.

Educação e Realidade, Porto Alegre, v. 35, n. 3, p. 37-58, 2010. Disponível em: https:// seer.ufrgs.br/educacaoerealidade/article/view/13077. Acesso em: 24 jun. 2021. 
FRASSON, Antônio Carlos; OLIVEIRA JUNIOR, C. R. Metodologia da pesquisa científica. São Luís: Uemanet, 2010. Disponível em: https://ava2.uemanet.uema.br/ pluginfile.php/63226/mod_resource/content//Fasc\%C3\%ADculo\%20\%20Metodolog ia\%20Cient\%C3\%ADfica.pdf. Acesso em: 8 jun. 2021.

GEWEHR, Diógenes. Tecnologias digitais de informação e comunicação (TDICs) na escola e em ambientes não escolares. Lajeado: UNIVATES, 2016. Disponível em: https://www.univates.br/bdu/bitstream/10737/1576/1/2016

DiogenesGewehr.pdf. Acesso em: 20 nov. 2020.

LAKATOS, Eva Maria; MARCONI, Marina de Andrade. Fundamentos de metodologia científica. 5. ed., São Paulo: Atlas, 2003.

LUCK, Heloísa. Dimensões de gestão escolar e suas competências. Curitiba: Editora Positivo, 2009.

PEREIRA, Bernadete Terezinha. $O$ uso das tecnologias da informação e comunicação na prática pedagógica da escola. Paraná: UFPR, 2008. Disponível em: http://www. diaadiaeducacao.pr.gov.br/portals/pde/arquivos/1381-8.pdf. Acesso em: 13 nov. 2020.

PRODANOV, Cleber Cristiano.; FREITAS, Ernani Cesar de. Metodologia do trabalho científico [recurso eletrônico]: métodos e técnicas da pesquisa e do trabalho acadêmico. 2. ed. Novo Hamburgo: Feevale, 2013.

VEDOVATTO, Dijnane Fernanda Iza et al. Identidade docente: as várias faces da constituição do ser professor. Revista Eletrônica de Educação. São Carlos, v. 8, p. 273292, 2014. Disponível em: http://www.reveduc.ufscar.br/index.php/reveduc/ article/view/978. Acesso em: 11 maio. 2021.

ZACARIOTTI, Marluce. E. C.; SOUSA, José Luis dos Santos. Tecnologias digitais de informação e comunicação como recurso de mediação pedagógica. Revista Observatório, Tocantins, v. 5, n. 4, p. 613-633, 2019. Disponível em: https://sistemas.uft. edu.br/periodicos/index.php/observatorio/article/view/4674. Acesso em: 20 maio. 2021.

ZANON, D. P; MENDES, M. E. B. A aula: a aula: momento de pensar, refletir, agir! Paraná: Secretaria da Educação do Estado do Paraná, 2009. Disponível em: http://www. diaadiaeducacao.pr.gov.br/portals/pde/arquivos/38-4.pdf. Acesso em: 30 abr. 2021.

Recebido em 19 de outubro de 2021 Aprovado em 25 de novembro de 2021 